\title{
A probabilistic seismic hazard assessment for Greece and the surrounding region including site-specific considerations
}

\author{
Theodoros M. Tsapanos ( $\left.{ }^{1}\right)$, Päivi Mäntyniemi $\left({ }^{2}\right)$ and Andrzej Kijko $\left({ }^{3}\right)$ \\ ${ }^{1}{ }^{1}$ Aristotle University of Thessaloniki, School of Geology, Geophysical Laboratory, Thessaloniki, Greece \\ ${ }^{(2)}$ Institute of Seismology, University of Helsinki, Finland \\ $\left(^{3}\right)$ Council for Geoscience, Pretoria, South Africa
}

\begin{abstract}
A probabilistic approach was applied to map the seismic hazard in Greece and the surrounding region. The procedure does not require any specification of seismic sources or/and seismic zones and allows for the use of the whole seismological record, comprising both historical and instrumental data, available for the region of interest. The new seismic hazard map prepared for Greece and its vicinity specifies a $10 \%$ probability of exceedance of the given Peak Ground Acceleration (PGA) values for shallow seismicity and intermediate soil conditions for an exposure time of 50 years. When preparing the map, the new PGA attenuation relation given by Margaris $e t$ al. (2001) was employed. The new map shows a spatial distribution of the seismic hazard that corresponds well with the features of shallow seismicity within the examined region. It depicts the level of seismic hazard in which the exceedance of the PGA value of $0.25 \mathrm{~g}$ may be expected to occur within limited areas. The highest estimated levels of seismic hazard inside the territory of Greece are found in the Northern Sporades Islands, where PGA values in excess of $0.50 \mathrm{~g}$ are reached at individual sites, and in the Zante Island in Western Greece, where PGA values in the range of $0.35 \mathrm{~g}$ to $0.40 \mathrm{~g}$ are obtained at more numerous localities. High values are also observed in the sea between the Karpathos and Rhodes islands, near the Island of Amorgos (Cyclades Archipelago) and in the Southwestern Peloponnesus. The levels of seismic hazard at the sites of seven Greek cities (Athens, Jannena, Kalamata, Kozani, Larisa, Rhodes and Thessaloniki) were also estimated in terms of probabilities that a given PGA value will be exceeded at least once during a time interval of 1,50 and 100 years at those sites. These probabilities were based on the maximum horizontal PGA values obtained by applying the design earthquake procedure, and the respective median values obtained were $0.24 \mathrm{~g}$ for Athens, $0.28 \mathrm{~g}$ for Jannena, $0.30 \mathrm{~g}$ for Kalamata, $0.21 \mathrm{~g}$ for Kozani, $0.24 \mathrm{~g}$ for Larisa, $0.43 \mathrm{~g}$ for Rhodes and $0.35 \mathrm{~g}$ for Thessaloniki. The probabilities of exceedance of the estimated maximum possible PGA value were also calculated for the cities to illustrate the uncertainty of maximum PGA assessment.
\end{abstract}

Key words seismicity of Greece - probabilistic seismic hazard - peak ground acceleration - design earthquake procedure

Mailing address: Dr. Päivi Mäntyniemi, Institute of Seismology, University of Helsinki, P.O. Box 68, FI-00014, Helsinki, Finland; e-mail: paivi.mantyniemi@ seismo.helsinki.fi

\section{Introduction}

The basic lithospheric process in the Aegean Sea is the subduction of the African plate under the Eurasian plate south of the Island of Crete, forming the Hellenic Arc and Trench (Papazachos and Comninakis, 1971; Comninakis and Papazachos, 1972; Makris, 1973; Mercier, 1977; McKenzie, 1978; Dewey and Sengor, 1979; Makropoulos and Burton, 1984). Because of this process, Greece is one of 
the most seismically active regions in the world. In one ranking of 50 seismogenic countries worldwide, Greece took the sixth position (Tsapanos and Burton, 1991).

The objective of seismic hazard assessment is to obtain long-term probabilities of the occurrence of seismic events of a specified size in a given time interval. A large number of approaches are currently available for this purpose. Abundant literature on the seismic hazard in Greece therefore exists for a number of different seismic quantities such as the maximum expected macroseismic intensity (Shebalin et al., 1976; Papaioannou, 1984; Papoulia and Slejko, 1997), Peak Ground Acceleration (PGA) or velocity (Algermissen et al., 1976; Makropoulos and Burton, 1985) and the duration of strong ground motion (Margaris et al., 1990; Papazachos et al., 1992). One version of the geographic distribution of seismic hazard in Greece, based on seismic sources, has been provided by Papazachos et al. (1993). Main and Burton (1989) estimated the seismicity in Greece by considering two different processes, namely subduction and stretching. Seismic hazard parameters have been calculated for Greece using the maximum likelihood method ( $\mathrm{Pa}-$ padopoulos and Kijko, 1991), while Papaioannou and Papazachos (2000) estimated the seismic hazard using new seismotectonic data.

In the present work, the seismic hazard in Greece was assessed in terms of PGA using the approach described in Kijko and Graham (1998, 1999) and using the recent Greek attenuation relationship derived by Margaris et al. (2001). Seismic hazard analysis was done on the basis of the whole seismological record available for Greece, including historical observations as well as the instrumental data recorded during the past decades, covering a period of about two and a half millennia and comprising some 600 destructive earthquakes (Papazachos and Papazachou, 1997). Only the shallow seismicity was taken into consideration, because the attenuation relationship given by Margaris et al. (2001) was derived for shallow earthquakes, and they account for the vast majority of the observed events. A seismic hazard map was created for the Greek territory. In this map, the estimated seismic hazard is specified in terms of the PGA with a $10 \%$ probability of exceedance in 50 years, corresponding to a return period of 475 years. In addition, a detailed analysis of seismic hazard was carried out for the Greek cities of Athens, Jannena, Kalamata, Kozani, Larisa, Rhodes and Thessaloniki. This included an assessment of the maximum possible PGA at the sites of the cities and the calculation of the probabilities that a given PGA value will be exceeded at least once during time intervals of 1, 50 and 100 years at each site. The maximum PGA values for the seven sites were obtained by applying the design earthquake procedure, assuming the occurrence of the strongest possible earthquake at the distance of $15 \mathrm{~km}$ from the site. The probabilities of exceedance of the maximum possible PGA values were also calculated to illustrate the uncertainty of maximum PGA estimation.

\section{The data}

The examined region covers the territory of Greece and its vicinity, including the Greek mainland, parts of its northern contiguous countries, the Aegean Sea and Western Turkey, between latitudes $33.0^{\circ}-43.0^{\circ} \mathrm{N}$ and longitudes $19.0^{\circ}-29.0^{\circ} \mathrm{E}$. Figure 1 shows the epicentres of shallow main shocks of magnitude $M \geq 5$ for this region.

Information on the seismicity of Greece exists from the 6th century B.C. onwards, as descriptions of earthquake effects were made by the ancient Greeks, Romans and Byzantines. The data used in the present study were retrieved from the databank of the Geophysical Laboratory of the University of Thessaloniki. This databank comprises information on a large number of Greek earthquakes since 550 B.C. (Papazachos et al., 2000). As knowledge of the completeness, homogeneity and accuracy of earthquake data is necessary for a reliable estimation of various seismicity parameters, the uncertainties and thresholds for complete reporting were assessed as follows: the catalogue of shallow seismicity is complete for the area under investigation for magnitudes $M \geq 8.0$ since 550 B.C., for $M \geq 7.3$ since 1501 A.D., $M \geq 6.0$ since $1845, M \geq 5.0$ since $1911, M \geq 4.5$ 


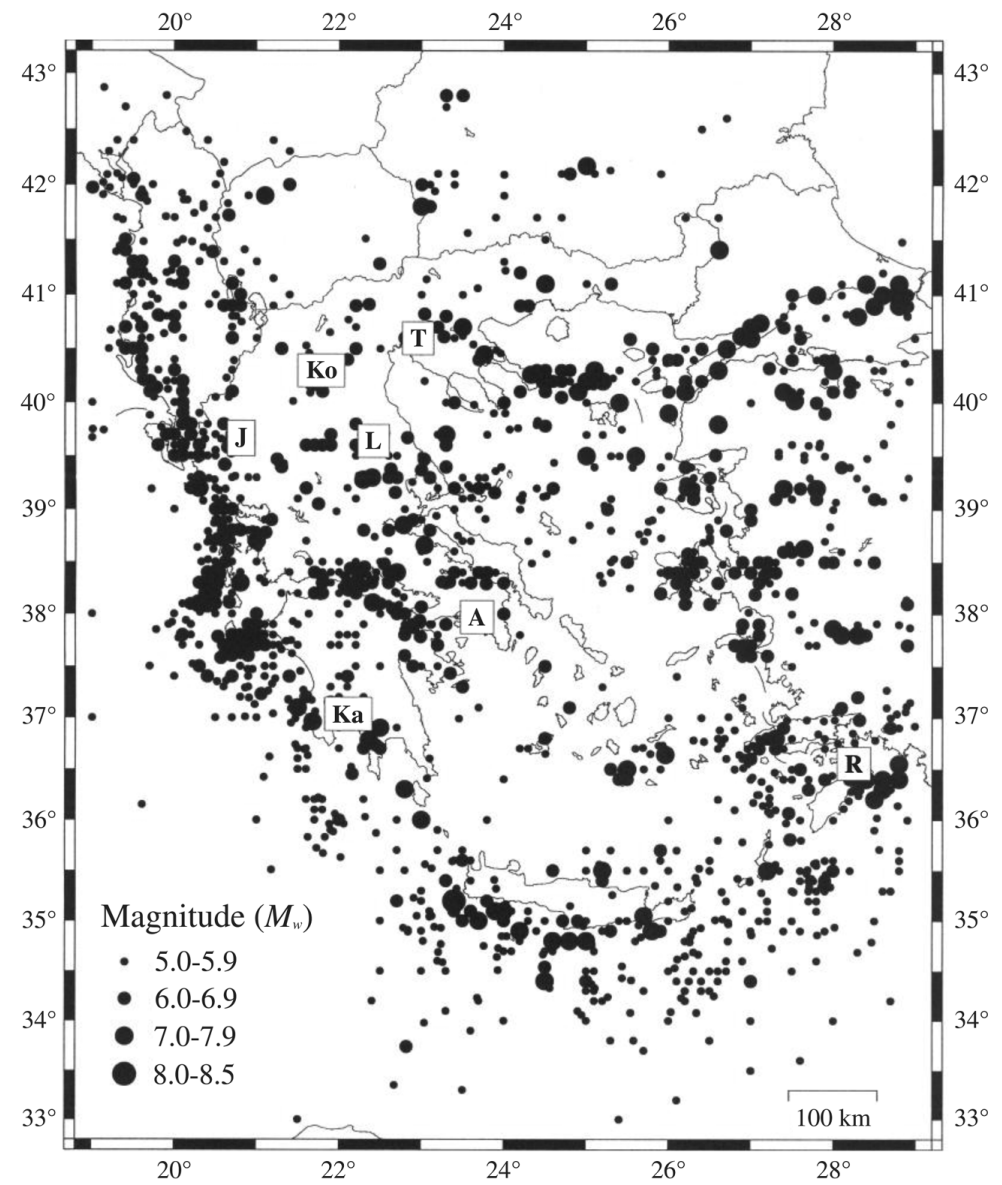

Fig. 1. An epicentre map of shallow main shocks of magnitude $M_{w} \geq 5$ for Greece and the surrounding region between 550 B.C. and 1999. The letters mark the sites of the cities of Athens, Jannena, Kalamata, Kozani, Larisa, Rhodes and Thessaloniki for which site-specific analyses of seismic hazard were performed.

since $1950, M \geq 4.3$ since 1964 and for magnitudes $M \geq 4.0$ since 1981 (Papazachos et al., 2000). All magnitudes are given on a scale equivalent to the moment magnitude (for more details see: Papazachos et al., 1997). During the instrumental measurement era after 1911, the error for the epicentres is less than $20 \mathrm{~km}$, while the uncertainty of magnitudes is 0.25 magnitude units (Papazachos and Papazachou, 1997). The errors affecting the historical data between 550 B.C. and 1910 are of the same order, mainly because these were strong shocks with substantial macroseismic information available. Thus, for the historical earthquakes the uncertainties for the epicentre and magnitude are less than $30 \mathrm{~km}$ and 0.4 magnitude units, respectively (Papazachos and Papazachou, 1997). If the number of macroseismic observations available for an event is less than ten, the uncertainty of magnitude may reach 0.5 magnitude units.

In the present study, foreshocks, aftershocks and earthquake swarms were omitted from the initial earthquake catalogue. This removal was based on a relationship derived by Papazachos 
and Papazachou (1997), in which the duration of the aftershock sequence depends on the magnitude of the main shock. The remaining shallow main events served as the input data for the seismic hazard analyses.

\section{Outline of the methodology}

The method used to estimate the level of seismic hazard in terms of PGA has been described in detail in Kijko and Graham (1998, 1999). The first part of their work focuses on the development and presentation of statistical techniques that can be used for the evaluation of the maximum regional magnitude, $m_{\max }$. The second part delineates a methodology for probabilistic seismic hazard assessment at a given site. In the present study, emphasis is placed on the second aspect.

Site-specific analyses of seismic hazard require a knowledge of the attenuation of the selected ground-motion parameter $a$, usually PGA, as a function of earthquake magnitude and distance. According to the adopted methodology, the attenuation relationship of PGA is assumed to be of the type

$$
\ln (a)=c_{1}+c_{2} \cdot m+\phi(r)+\varepsilon
$$

where $c_{1}$ and $c_{2}$ denote empirical coefficients, $m$ is the earthquake magnitude, $\phi(r)$ is a function of earthquake distance and $\varepsilon$ is a normally distributed random error.

To express seismic hazard in terms of PGA, the aim would be to calculate the conditional probability that an earthquake of random magnitude, occurring at a random distance from the site, will cause a PGA value equal to, or greater than, the chosen threshold value, $a_{\min }$, at the site. We accept the standard assumption (e.g., Page, 1968) that the random earthquake magnitude $m$, in the range of $m_{\min } \leq m \leq m_{\max }$, is distributed according to the doubly truncated Gutenberg-Richter relation with a Cumulative Distribution Function (CDF) of

$$
F_{M}(m)=\frac{\exp \left(-\beta m_{\min }\right)-\exp (-\beta m)}{\exp \left(-\beta m_{\min }\right)-\exp \left(-\beta m_{\max }\right)} .
$$

In eq. (3.2), $m_{\min }$ is the minimum earthquake magnitude corresponding to $a_{\mathrm{min}}$, which is the minimum value of PGA of engineering interest at the site, $m_{\max }$ is the maximum credible earthquake magnitude and $\beta=b \ln 10$, where $b$ is the parameter of the Gutenberg-Richter magnitudefrequency relation. It can be shown (Kijko and Graham, 1999) that choosing eq. (3.1) as a model for attenuation of PGA and eq. (3.2) as a distribution of earthquake magnitude, is equivalent to the assumption that the CDF of the logarithm of PGA, $x$, is of the form

$$
F_{X}(x)=\frac{\exp \left(-\gamma x_{\min }\right)-\exp (-\gamma x)}{\exp \left(-\gamma x_{\min }\right)-\exp \left(-\gamma x_{\max }\right)}
$$

Above, $x_{\min }=\ln \left(a_{\min }\right), x_{\max }=\ln \left(a_{\max }\right), a_{\max }$ is the maximum possible PGA at the site, $\gamma=\beta / c_{2}$ where $c_{2}$ is the coefficient related to the attenuation formula (3.1) and $\beta$ is the parameter related to the Gutenberg-Richter distribution of earthquake magnitude (3.2). One should note that CDF (3.3) was derived under the condition that the spatial and magnitude distributions are mutually independent. In practice, the assumptions of independence mean that within the area surrounding the specified site, the parameters of earthquake magnitude distribution $m_{\min }, m_{\max }$ and $\beta$ are the same.

It can be seen from formula (3.3) that the logarithm of the PGA at a given site follows the same type of distribution as the earthquake magnitude, i.e. doubly truncated negative exponential - the form of the Gutenberg-Richter distribution in eq. (3.2). The two distributions differ only in the value of their parameters. If the parameter of the magnitude distribution is equal to $\beta$, the parameter of the distribution of $x=\ln (\mathrm{PGA})$ is equal to $\beta / c_{2}$.

From an engineering point of view, the largest PGA expected at least once at a given site during a specified time interval, $t$, is of special interest. The CDF of the logarithm of the largest PGA value, $x$, to be observed at least once at the site during a specified time interval $t$, can be written as

$$
F_{X}^{\max }(x \mid t)=\frac{\exp \left\{-\lambda t\left[1-F_{X}(x)\right]\right\}-\exp (-\lambda t)}{1-\exp (-\lambda t)}
$$


where $\lambda$ is the site-specific activity rate of earthquakes that cause a PGA value, $a$, at the site, exceeding the threshold value $a_{\text {min }}$. Clearly, this CDF of the largest PGA values is doubly truncated: from below, by $x_{\min }=\ln \left(a_{\min }\right)$, and from above, by $x_{\max }=\ln \left(a_{\max }\right)$. The distribution in eq. (3.4) was derived under the assumption that the earthquakes that cause a PGA value $a$, $a \geq a_{\min }$, at the site are distributed according to the Gutenberg-Richter relation (3.2) and, in time, follow the Poisson process with mean activity rate $\lambda(x)=\lambda\left[1-F_{X}(x)\right]$, where $x=\ln (a)$.

The maximum likelihood method is used to estimate the site-characteristic seismic hazard parameters $\lambda$ and $\gamma$. If $a_{1}, \ldots, a_{n}$ are the largest PGA values recorded at the site during $n$ successive time intervals $t_{1}, \ldots, t_{n}$, the likelihood function of the sample $x_{1}, \ldots, x_{n}$, where $x_{i}=\ln \left(a_{i}\right)$ and $i=1, \ldots, n$, for a specified value $a_{\max }$ can be written as

$$
L(\lambda, \gamma)=\prod_{i=1}^{n} f_{X}^{\max }\left(x_{i} \mid t_{i}\right)
$$

where $f_{X}^{\max }\left(x_{i} \mid t_{i}\right)$ is the probability density function of the logarithm of the largest PGA value observed at a given site during a given time interval $t$. By definition, the probability density function $f_{X}^{\max }\left(x_{i} \mid t_{i}\right)=\mathrm{d} F_{X}^{\max }\left(x_{i} \mid t_{i}\right) / \mathrm{d} x$. For a given value of $x_{\max }$ (or equivalently, the maximum possible PGA at the site), maximisation of the likelihood function (3.5) leads to the determination of the parameters $\lambda$ and $\gamma$. However, this procedure for the estimation of the hazard parameters is used only when the $b$-value (or equivalently $\beta$ ) of the Gutenberg-Richter frequency-magnitude relationship is not known. When the $b$-value is known, parameter $\gamma$ is calculated as $\beta / c_{2}$ and the maximum likelihood search (3.5) reduces to the estimation of the site-specific, mean seismic activity rate $\lambda$. In order to create seismic hazard maps, the procedure is repeatedly applied to grid points covering the area of interest.

\section{Attenuation relationship}

A new attenuation relationship has recently been proposed for Greece and the surrounding region by Margaris et al. (2001). They used a data set consisting of records of 142 mainly normal faulting earthquakes with magnitudes in the range of $4.5<M_{w}<7.0$ and epicentral distances between 1 and $150 \mathrm{~km}$ to derive the attenuation relationship. A total of 744 records of horizontal components and 338 records of vertical components of the peak ground acceleration, velocity and displacement were available. They took into consideration only the shallow earthquakes within the examined region. They considered soil classification according to the NEHRP (1994) recommendations and suggested empirical predictive relations for the horizontal components of strong ground motion.

The new attenuation relation for PGA takes the following form:

$$
\begin{aligned}
& \ln (\mathrm{PGA})=c_{1}+c_{2} \cdot M_{w}+c_{3} . \\
& \cdot \ln \left(D^{2}+h_{0}^{2}\right)^{1 / 2}+c_{4} \cdot S \pm c_{5} .
\end{aligned}
$$

Above, $D$ is epicentral distance (in $\mathrm{km}$ ) and $h_{0}=$ $=7 \mathrm{~km}$. The parameters of the model are $c_{1}=$ $=-3.36, c_{2}=0.70, c_{3}=-1.14$ and $c_{4}=0.12$ and the standard deviation of $\ln (\mathrm{PGA})$ is $c_{5}=0.70$. With these values, the attenuation relationship of eq. (4.1) provides acceleration values in units of $\mathrm{g}$. The constant $c_{3}$ in front of the term $\ln \left(D^{2}+\right.$ $\left.+h_{0}^{2}\right)^{1 / 2}$ includes both anelastic and geometric attenuation. The letter $S$ describes soil classification by taking values 0,1 or 2 , corresponding to rock (hard), intermediate and alluvium (soft) conditions, respectively.

Earlier attenuation relationships for the Greek territory were proposed by Makropoulos and Burton (1985), following Makropoulos (1978), and also by Papaioannou (1984). The relationships derived by Theodoulidis (1991) were regarded as the official attenuation relationship for Greece during the 1990s. In order to obtain more insight into the most recent attenuation relation given by Margaris et al. (2001), it was compared with the previous relationships. Figure $2 \mathrm{a}-\mathrm{c}$ shows the acceleration values as a function of distance computed according to the four different relationships for three different magnitudes assuming intermediate soil conditions. It can be seen that the new attenuation relationship gives lower values than 


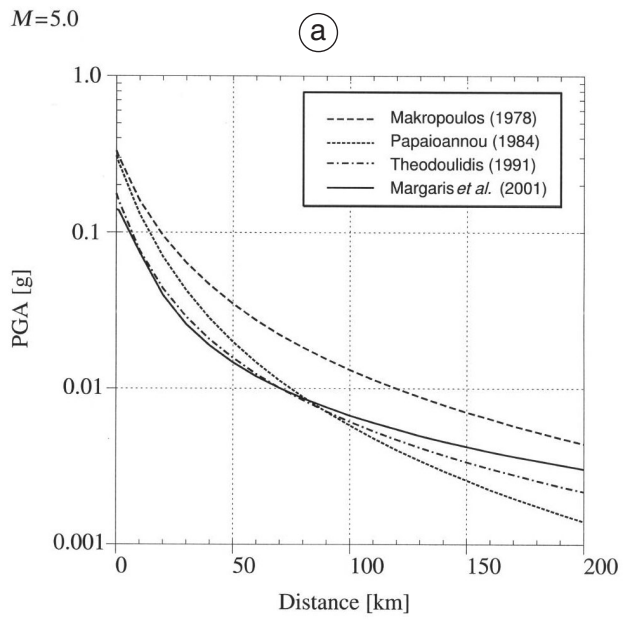

$M=6.0$

(b)

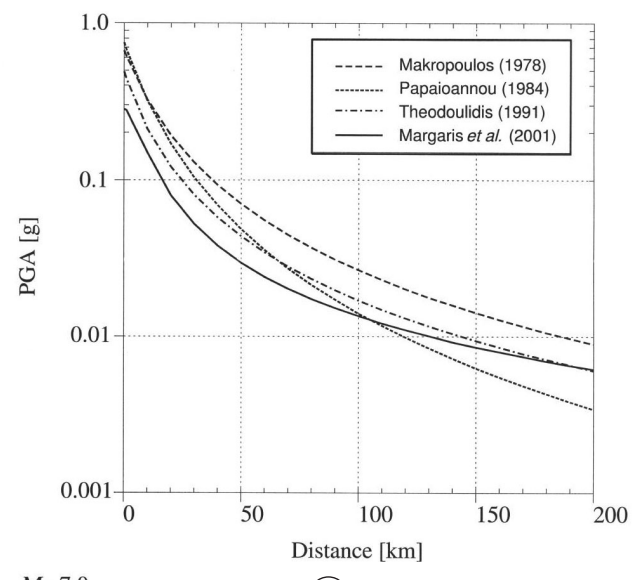

$M=7.0$

(C)

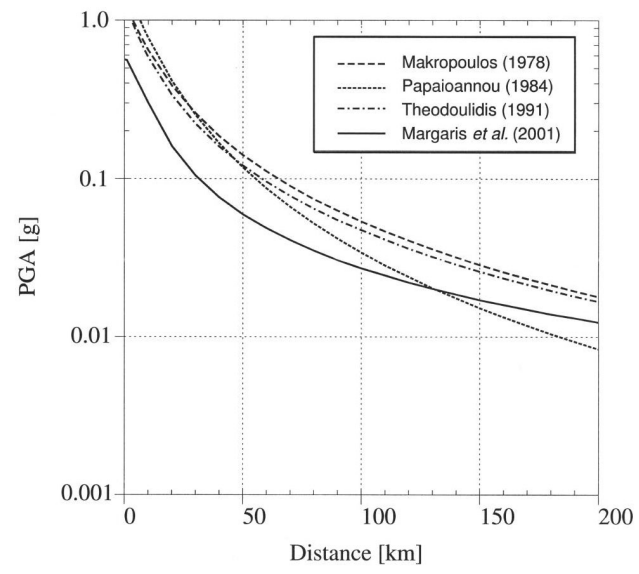

Fig. 2a-c. A comparison of Peak Ground Acceleration (PGA) values as a function of distance for magnitudes (a) $M_{w}=5.0$, b) $M_{w}=6.0$ and (c) $M_{w}=7.0$ computed for intermediate soil conditions according to the new Greek attenuation relationship given by Margaris et al. (2001) and the relationships proposed earlier for Greece by Makropoulos (1978), Papaioannou (1984) and Theodoulidis (1991).

the other relationships especially at near distances. This is most pronounced in the case of $M_{w}=7.0$, when the acceleration values based on the most recent relation are the lowest up to a distance of $130 \mathrm{~km}$. For magnitudes $M_{w}=5.0$ and $M_{w}=6.0$, the corresponding distances are $80 \mathrm{~km}$ and $100 \mathrm{~km}$, respectively. For magnitudes $M_{w}=6.0$ and $M_{w}=7.0$, only the relationship proposed by Papaioannou (1984) gives lower acceleration values for large distances than the most recent relationship, whereas for magnitude $M_{w}=5.0$ also the acceleration values from the relationship of Theodoulidis (1991) are lower for distances in excess of $80 \mathrm{~km}$. A comparison between the attenuation relationships of Theodoulidis (1991) and of Margaris et al. (2001) shows that the difference between computed acceleration values increases with increasing magnitude. For example, for a distance of $20 \mathrm{~km}$, assuming intermediate soil conditions and a magnitude $M_{w}=5.0$, the difference between median PGA values is only $0.0042 \mathrm{~g}$; for $M_{w}=6.0$ it is $0.042 \mathrm{~g}$ and for $M_{w}=7.0$ it is $0.18 \mathrm{~g}$, the higher values resulting from the earlier attenuation relationship.

The recent Greek attenuation relationship, eq. (4.1), was also compared with that derived for the European territory by Ambraseys et al. (1996). Since this relation only provides acceleration for magnitudes expressed on the $M_{s}$ scale, the version given by Wahlström and Grünthal (2001), with $M_{s}$ converted to $M_{w}$, was used. The PGA values were computed as a function of distance for the magnitude $M_{w}=6.0$ and a focal depth of $7 \mathrm{~km}$ assuming hard rock conditions (fig. 3). It can be seen that the median values of acceleration (corresponding to $p=0$ ) given by the Greek relation are considerably lower than the values computed according to the Ambraseys et al. (1996) relationship for 


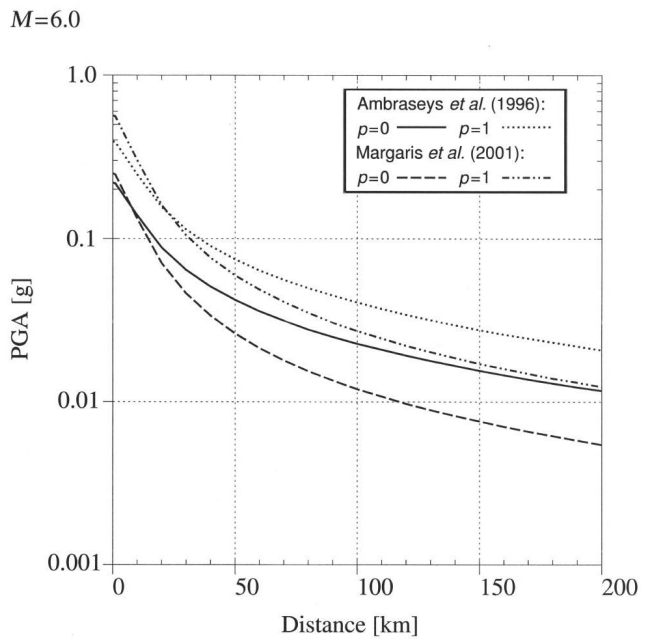

Fig. 3. A comparison of Peak Ground Acceleration (PGA) values as a function of distance for the magnitude $M_{w}=6.0$ and a focal depth of $7 \mathrm{~km}$ computed according to the new Greek attenuation relationship given by Margaris et al. (2001) and that derived for the European territory by Ambraseys et al. (1996). The displayed PGA values were computed for hard rock conditions. Notation $p=0$ stands for median PGA values, whereas in the case of $p=1$ the PGA values were computed by taking into account the standard deviation of the normal distribution of $\ln$ (PGA), corresponding to the 84th percentile level of non-exceedance.

distances in excess of $5 \mathrm{~km}$. The Greek values corresponding to the 84th percentile level $(p=1)$, computed by taking into account the standard deviation of the normal distribution of $\ln (\mathrm{PGA})$, are lower than those computed with Ambraseys et al. (1996) relationship for distances larger than about $20 \mathrm{~km}$. This behaviour was also observed for magnitudes $M_{w}=5.0$ and $M_{w}=7.0$.

\section{Results and discussion}

\subsection{Seismic hazard map}

Figure 4 shows the new seismic hazard map for Greece, computed according to the above procedure and the recently developed attenuation relation (4.1). The seismic hazard is expressed in terms of PGA values with a $10 \%$ probability of exceedance at least once in 50 years, corresponding to a return period of 475 years. The map was prepared for shallow seismicity, assuming intermediate soil conditions and using a grid point mesh of $0.20^{\circ}$. The $b$ parameter was assumed to take the constant value $b=1$ over the whole region of interest (see, e.g., Papazachos and Papazachou, 1997).

The overall spatial distribution of seismic hazard as depicted in the map corresponds well with the main features of tectonics and shallow seismicity in the examined region. A belt of increased seismic hazard runs along the Hellenic Trench, the Island of Crete and in Western Greece, continuing north into Albania, whereas its eastern part joins the west coast of Turkey. This zone is related to the active convergent boundary between the Aegean and the African plates in the south and to the continental collision between Apulia and the Aegean in the west. The highest estimated levels of seismic hazard in this zone are located in the Zante Island in Western Greece. High values are also observed in the sea between the Karpathos and Rhodes islands, near the Island of Amorgos (Cyclades Archipelago) and in the Southwestern Peloponnesus. The highest estimated levels of seismic hazard inside the territory of Greece are found in the Northern Sporades Islands, which corresponds to the western termination of the North Anatolian Fault. Intermediate values dominate in the Gulf of Corinth, in the Athos Peninsula (ChalkidikiNorthern Greece), Thessaloniki and in the Ionian Islands. Northeastern Greece, the Sea of Crete and Northwestern Greece appear as areas of the lowest seismic hazard. Most of the zone of increased seismic hazard corresponding to the Hellenic Arc and Trench, as well as the North Aegean and Western Turkey, shows PGA values in the range of $0.20 \mathrm{~g}$ to $0.25 \mathrm{~g}$, while values in excess of $0.25 \mathrm{~g}$ are reached within limited areas. The maximum computed PGA values inside the territory of Greece are in excess of $0.50 \mathrm{~g}$ and can be found at individual sites in the Northern Sporades Islands, whereas PGA values in the range of $0.35 \mathrm{~g}$ to $0.40 \mathrm{~g}$ are obtained at more numerous localities in the Ionian Islands. 


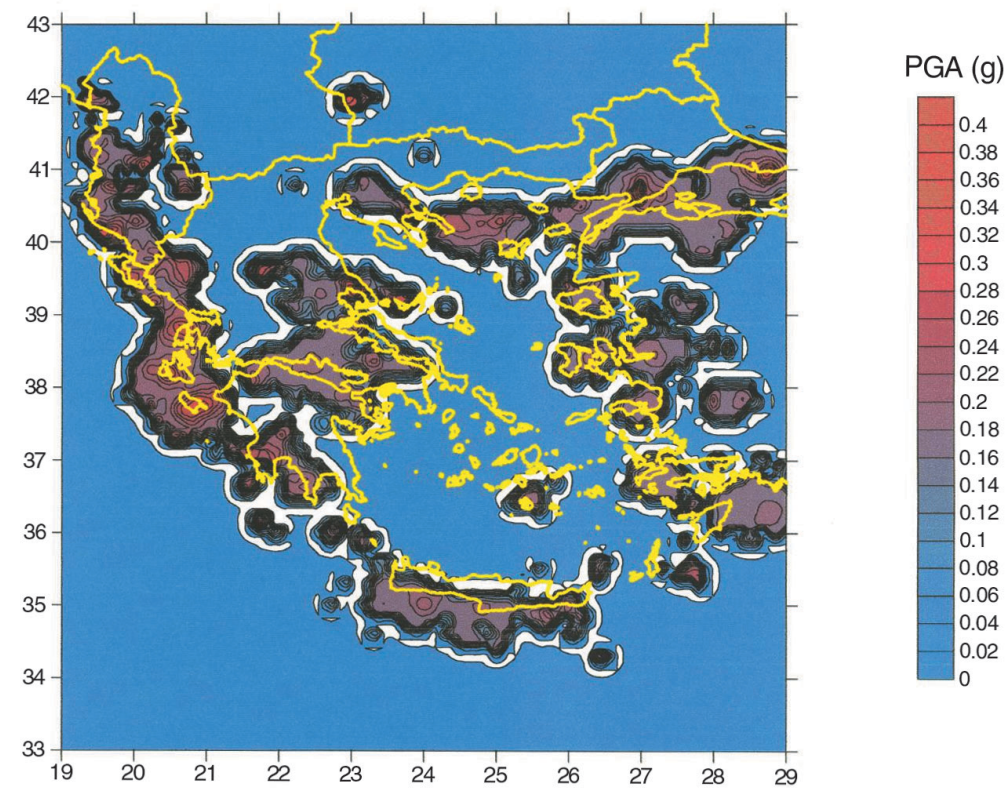

Fig. 4. A new seismic hazard map for Greece based on the attenuation relationship of Margaris et al. (2001). The hazard is expressed in terms of Peak Ground Accelaration (PGA) values for intermediate soil conditions with a $10 \%$ probability of exceedance at least once in 50 years.

Makropoulos and Burton (1985) presented seismic hazard maps for Greece in terms of PGA. They applied extreme value analyses and employed an attenuation relationship based on the averaging of eight formulae reported in worldwide studies. The spatial distribution of seismic hazard depicted in their maps is rather similar to that shown in fig. 4. Makropoulos and Burton (1985) obtained a high PGA hazard around Cephalonia and the Levkas islands as well as around Lesvos and the Northeastern Sporades Islands. They reported a $30 \%$ probability of the PGA exceeding $0.2 \mathrm{~g}$ in 50 years within these areas.

\subsection{Sites of the cities}

Figure 5a-g shows the probabilities of the given PGA values being exceeded within time intervals of 1, 50 and 100 years at the sites Athens, Jannena, Kalamata, Kozani, Larisa,

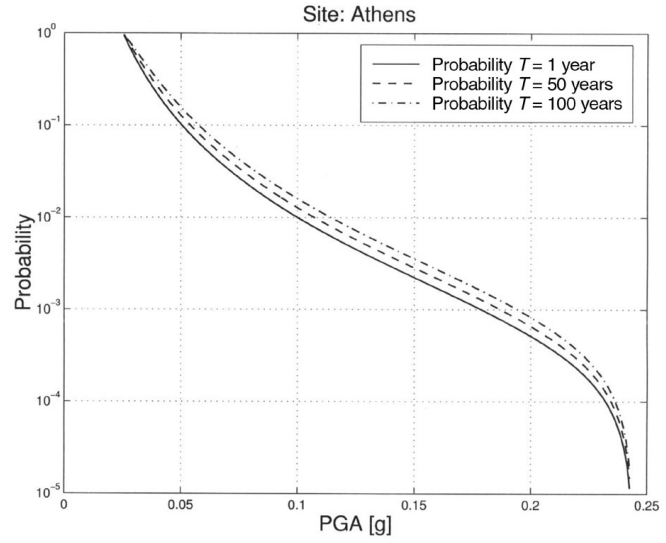

Fig. 5a. Probabilities that the given Peak Ground Acceleration (PGA) values will be exceeded in 1,50 and 100 years at the Athens site. The maximum PGA values are the median values obtained using the design earthquake procedure. 

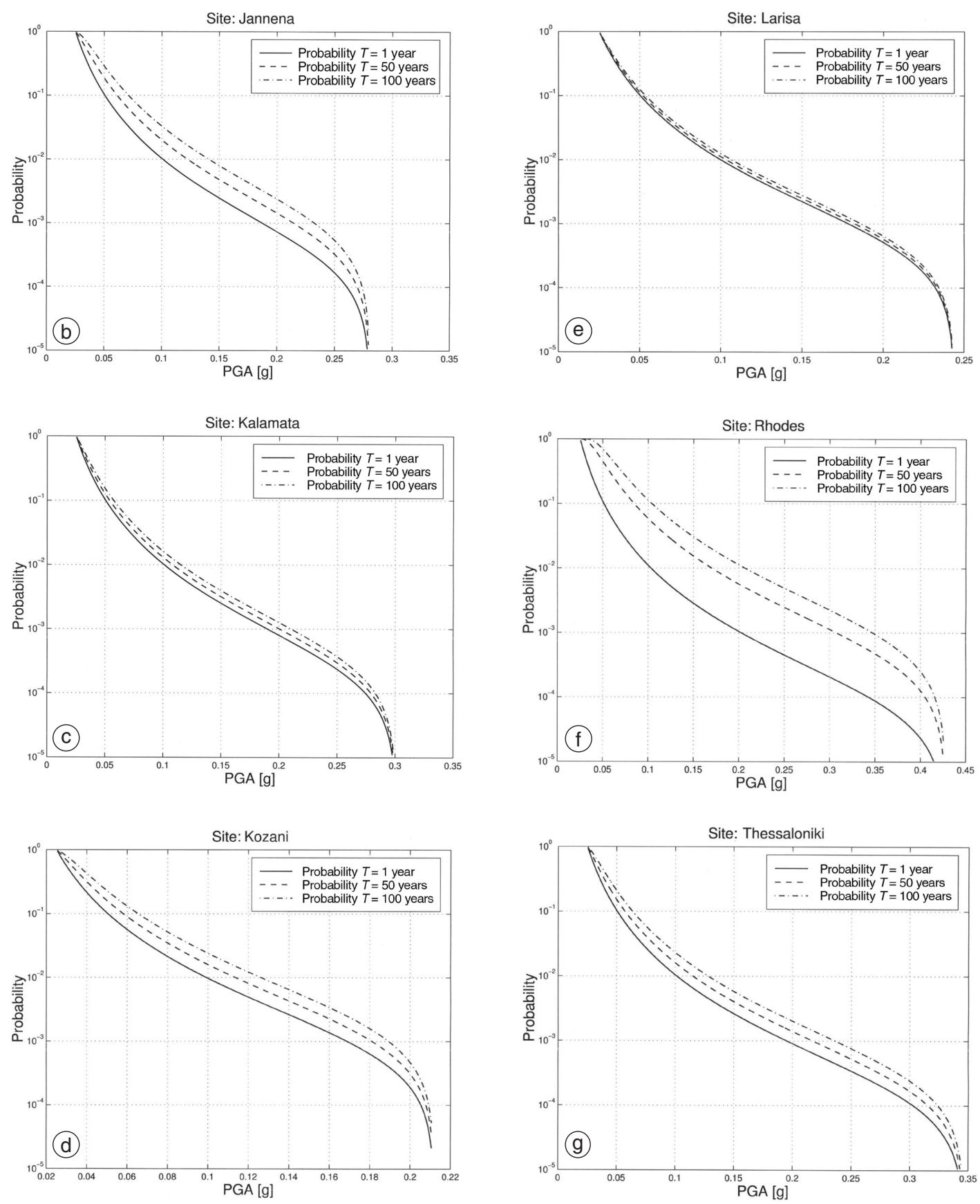

Fig. 5b-g. Probabilities that the given Peak Ground Acceleration (PGA) values will be exceeded in 1, 50 and 100 years at the sites: b) Jannena, c) Kalamata, d) Kozani, e) Larisa, f) Rhodes and g) Thessaloniki. The maximum PGA values are the median values obtained for each site using the design earthquake procedure. 


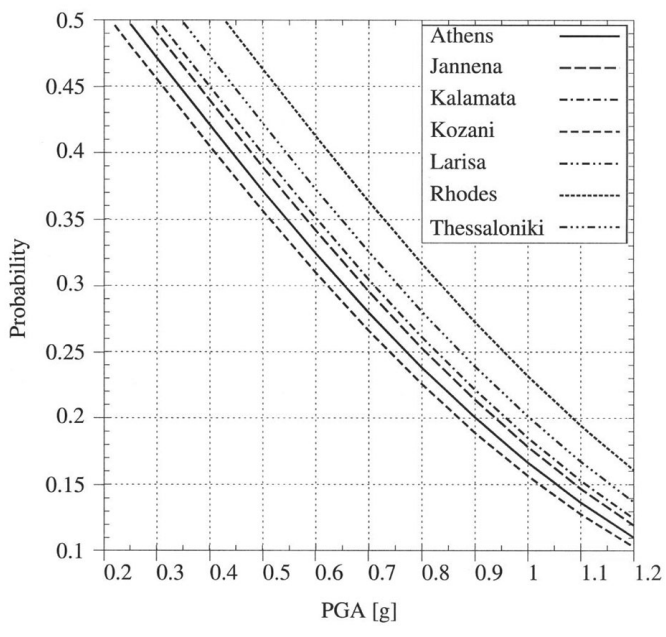

Fig. 6. The probabilities that an earthquake of maximum magnitude, as estimated for each area, will occur at a hypocentral distance of $15( \pm 5) \mathrm{km}$ from the respective site and produce a Peak Ground Acceleration (PGA) value exceeding the estimated maximum value at the sites Athens, Jannena, Kalamata, Kozani, Larisa, Rhodes and Thessaloniki. The probabilities computed for Athens and Larisa overlap.

Rhodes and Thessaloniki. These probability curves are based on the estimated values for $\gamma$, $\lambda$ and $a_{\max }$ in formulae (3.3) and (3.4). The values for the maximum possible PGA, $a_{\max }$, were obtained using the attenuation relation (4.1) and assuming the occurrence of the strongest possible earthquake, $\hat{m}_{\max }$, at a distance of $15 \mathrm{~km}$ from the site. The maximum credible magnitudes, $\hat{m}_{\max }$, were computed using data for a radius of $180 \mathrm{~km}$ from each city centre and the KS-B procedure (see Kijko and Graham, 1998: eq. 54). The maximum (median) PGA values, $a_{\max }$, were $0.24 \mathrm{~g}$ for Athens, $0.28 \mathrm{~g}$ for Jannena, $0.30 \mathrm{~g}$ for Kalamata, $0.21 \mathrm{~g}$ for Kozani, $0.24 \mathrm{~g}$ for Larisa, $0.43 \mathrm{~g}$ for Rhodes and $0.35 \mathrm{~g}$ for Thessaloniki. The probability plots for Athens and Thessaloniki can also be found in Mäntyniemi et al. (2004).

Figure 6 illustrates the uncertainty of maximum PGA assessment for the cities of Athens, Jannena, Kalamata, Kozani, Larisa, Rhodes and Thessaloniki. It gives the probabilities that an earthquake of maximum credible magnitude, as estimated for each area, will occur at a hypocentral distance of $15( \pm 5) \mathrm{km}$ from the respective site and produce a PGA value exceeding the estimated maximum value. In the calculations it was assumed that the standard deviation of estimated maximum values of the PGA is affected by three factors: 1) the uncertainty in determination of the earthquake epicentral distance; 2) the maximum earthquake magnitude $m_{\max }$ and 3) the uncertainty of attenuation relationship. This kind of approach can be regarded as a probabilistic extension of the deterministic, design-earthquake scenario. The probabilities obtained for the exceedance of a high PGA value, for example $0.70 \mathrm{~g}$, range between $36 \%$ for Rhodes and $27 \%$ for Kozani. The probabilities computed for Athens and Larisa overlap, and also the assessed maximum PGA values for these sites are the same.

The computed exceedance probabilities of the given acceleration values at the site of each city for an exposure time of 100 years are compared in fig. 7. Rhodes stands out from the other cities with the highest expected PGA ex-

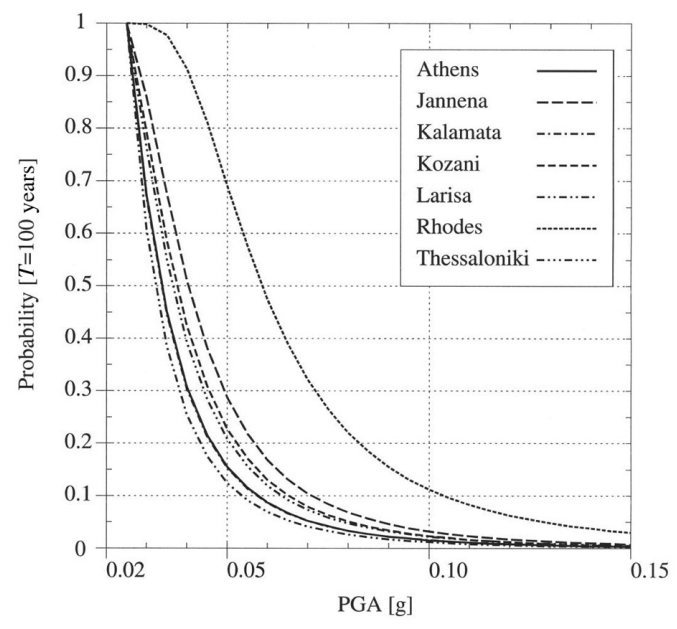

Fig. 7. The probabilities of exceedance of the given Peak Ground Acceleration (PGA) values at the sites Athens, Jannena, Kalamata, Kozani, Larisa, Rhodes and Thessaloniki during 100 years. The probability curves for Athens and Kalamata overlap. 
ceedance probabilities. The city of Jannena displays the second highest long-term probabilities, but they are much lower than those for Rhodes. Despite its proximity to the Hellenic Arc and Trench, Kalamata does not rank very high in the comparison. The computed probabilities for this site are practically identical to those for Athens, whereas higher values were obtained for the northern cities of Kozani and Thessaloniki. This is in contrast with expectations, as Kozani is situated in northwestern Greece, a region of negligible historical seismicity (Papazachos and Papazachou, 1997). The instrumentally recorded seismicity there seems to be mainly related to the filling of the artificial Lake Polyfytos (Papazachos et al., 1995). The area has been assumed to be of very low seismic hazard, and therefore the destructive Kozani earthquake $\left(M_{s}=6.6\right)$ of 13 May 1995 was quite unexpected (Papazachos et al., 1995). Northwestern Greece appears as an area of low seismic hazard also in fig. 4.

The seismicity features in areas adjacent to Thessaloniki seem to be characterised by earthquake sequences of long duration, extending to the northern contiguous countries (Papazachos et al., 1979). The city of Larisa has the lowest probabilities for the exceedance of the given PGA values. The probabilities computed for this site for exposure times of 1 and 100 years do not deviate very much from each other (fig. $5 \mathrm{~d}$ ), which can be attributed to the small activity parameter $\lambda_{S}$ for this site. The computed probabilities decrease rather quickly with increasing PGA values for all sites. For example, for the sites of Rhodes and Jannena, the PGA values with a $50 \%$ chance of exceedance within 100 years are $0.058 \mathrm{~g}$ and $0.040 \mathrm{~g}$, respectively (fig. 7).

Previous studies have also provided some estimates of seismic hazard in terms of the maximum expected PGA at the sites of the cities investigated in the present work. Makropoulos and Burton (1985) estimated ground-motion for the cities of Athens, Thessaloniki and Rhodes, among others. They applied extreme value analysis to compute ground acceleration values and to produce seismic hazard parameters. The acceleration values they reported that had a $70 \%$ probability of non-ex- ceedance for 50 and 100 years were, respectively, $0.09 \mathrm{~g}$ and $0.11 \mathrm{~g}$ for Athens, $0.15 \mathrm{~g}$ and $0.17 \mathrm{~g}$ for Thessaloniki and $0.075 \mathrm{~g}$ and $0.08 \mathrm{~g}$ for Rhodes. Thus, for the city of Rhodes their estimated PGA values are the lowest, although in terms of earthquake size the area surrounding this city has a high seismic potential. In the deterministic approach used to compute the $a_{\max }$ values of the PGA shown in fig. 5a-g, the maximum credible magnitude plays an important role, thus the highest $a_{\max }$ value is obtained for the site of Rhodes. Also the highest long-term probabilities for the exceedance of the given PGA values were obtained for this site (fig. 7).

Lyubushin et al. (2002) evaluated the level of seismic hazard in terms of maximum values of PGA for six sites in Greece, including Kalamata and Kozani, using a Bayesian procedure. They estimated a maximum PGA value of 0.36 $\mathrm{g}$ for Kalamata and $0.38 \mathrm{~g}$ for Kozani. The attenuation relationship of Theodoulidis (1991) was employed to derive these estimates. The maximum PGA values computed by Lyubushin et al. (2002) are higher than those estimated in the present study, which probably largely follows from the use of different attenuation relationships. As discussed in Section 4, the most recent attenuation relationship elucidated by Margaris et al. (2001) gives faster attenuation than do the previous Greek relations up to distances between $80-130 \mathrm{~km}$ depending on the magnitude.

Directly measured ground motion values became available following the magnitude $M_{w}=$ $=6.0$ event of 1986 near Kalamata (Anagnostopoulos et al., 1987) and the magnitude $M_{w}=$ $=6.6$ event of 1995 near Kozani (Theodoulidis and Lekidis, 1996). The observed value was $0.27 \mathrm{~g}$ for an epicentral distance of $12 \mathrm{~km}$ from Kalamata. The largest aftershock of the Kalamata earthquake was of magnitude $M_{w}=5.4$ and the respective recorded PGA value about $0.05 \mathrm{~g}$ at an epicentral distance of approximately $1 \mathrm{~km}$ (Anagnostopoulos et al., 1987). In the present study, the design earthquake procedure yielded a value of maximum PGA equal to $0.30 \mathrm{~g}$, based on the maximum credible magnitude of $7.50( \pm 0.25)$. This maximum magnitude exceeds the range of observed magnitudes available in the derivation of the PGA attenuation re- 
lationship of Margaris et al. (2001), and therefore the computed attenuation can be considered more uncertain than that for lower magnitudes. As displayed in fig. 6, the estimated maximum PGA values can be exceeded with the given probabilities. Also, the observed PGA value may have been affected by site effects, as Kalamata is built on the natural deposits of a dried up river (Anagnostopoulos et al., 1987). The measured ground motion value following the Kozani earthquake was $0.21 \mathrm{~g}$ for a distance of $19 \mathrm{~km}$ from the city (Theodoulidis and Lekidis, 1996), which equals the present value relying on a maximum credible magnitude of $7.0( \pm 0.25)$. Both the observed values for the Kalamata and Kozani main shocks are lower than the maximum PGA values estimated by Lyubushin et al. (2002).

\section{Conclusions}

In the present study, seismic hazard maps and site-specific assessments of seismic hazard were prepared for the territory of Greece including its vicinity and the sites of seven Greek cities (Athens, Jannena, Kalamata, Kozani, Larisa, Rhodes and Thessaloniki) using the methodology developed by Kijko and Graham (1998, 1999) and the recent PGA attenuation relationship derived for Greece by Margaris et al. (2001). The applied technique has been especially developed for probabilistic seismic hazard assessment at a specified site, and it does not rely on the definition of seismic sources and/or seismic zones. Only the shallow earthquakes were taken into consideration, because the attenuation relationship given by Margaris et al. (2001) was derived using them, and they account for the vast majority of the observed events. A seismic hazard map was created by applying the procedure repeatedly to grid points covering the area of interest. In the new map, the estimated seismic hazard is specified in terms of the horizontal PGA with intermediate soil conditions with a $10 \%$ probability of exceedance in 50 years. It depicts a spatial distribution of the seismic hazard that corresponds well with the features of shallow seismicity within the examined region. It shows a level of seismic hazard in which the exceedance of a PGA value of $0.25 \mathrm{~g}$ may be expected to occur within limited areas. The highest estimated levels of seismic hazard inside the territory of Greece are found in the Northern Sporades Islands, where PGA values in excess of $0.50 \mathrm{~g}$ are reached at individual sites, and around the Zante Island in Western Greece, where PGA values in the range of $0.35 \mathrm{~g}$ to $0.40 \mathrm{~g}$ are obtained at more numerous localities. High values are also observed in the sea between the Karpathos and Rhodes islands, near the Island of Amorgos (Cyclades Archipelago) and in the Southwestern Peloponnesus. Intermediate values dominate in the Gulf of Corinth, in the Athos Peninsula (Chalkidiki-Northern Greece), Thessaloniki and in the Ionian Islands. Northeastern Greece, the Sea of Crete and Northwestern Greece appear as areas of the lowest seismic hazard. The levels of seismic hazard at the sites of the seven Greek cities were assessed in terms of probabilities that a given PGA value will be exceeded at least once in 1, 50 and 100 years at the sites of the cities. The maximum (median) PGA values obtained by applying the design earthquake approach were $0.24 \mathrm{~g}$ for Athens, $0.28 \mathrm{~g}$ for Jannena, $0.30 \mathrm{~g}$ for Kalamata, $0.21 \mathrm{~g}$ for Kozani, $0.24 \mathrm{~g}$ for Larisa, $0.43 \mathrm{~g}$ for Rhodes and $0.35 \mathrm{~g}$ for Thessaloniki. The probabilities of exceedance of the estimated maximum possible PGA values were also calculated for the cities to illustrate the uncertainty involved in this kind of assessment. Some of the directly measured PGA values found in the literature exceed those obtained through the design earthquake procedure, although the respective observed earthquakes were only of moderate magnitude. This discrepancy can probably in part be attributed to site effects. Also, the recent Greek attenuation relationship employed in this study predicts rather rapid decrease in median PGA values as a function of distance in comparison with many previously published attenuation formulae. This applies especially to large earthquake magnitudes. The maximum credible magnitudes used in the design earthquake procedure also exceed the range of observed magnitudes available for its derivation, which adds to the uncertainty of the computed acceleration values. 


\section{REFERENCES}

Algermissen, S.T., D.M. Perkins, W. Isherwood, D. CoRDON, G. REAGOR and C. HowARD (1976): Seismic risk evaluation of the Balkan region, in Proceedings of the Seminar on Seismic Zoning Maps, Skopje, Yugoslavia, 1975, vol. 2, 172-240.

Ambraseys, N.N., K.A. Simpson and J.J. Bommer (1996): Prediction of horizontal response spectra in Europe, Earthq. Eng. Struct. Dyn., 2, 371-400.

Anagnostopolous, S.A., D. Rinaldis, V.A. LeKIDIS, V.N MARGARIS and N.P. THEODULIDIS (1987): The Kalamata, Greece, earthquake of September 13, 1986, Earthq. Spectra, 3, 365-402.

Comninakis, P.E. and B.C. PAPAZAChos (1972): Seismicity of the Eastern Mediterranean and some tectonic features of the Mediterranean ridge, Bull. Geol. Soc. Am. 83, 1093-1102.

Dewey, J.F. and A.M.C. Sengor (1979): Aegean and surrounding regions: complex multiplate and continous tectonics in a convergent zone, Bull. Geol. Soc. Am., 90, 84-92.

KiJKo, A. and G. GRAHAM (1998): Parametric-historic procedure for probabilistic seismic hazard analysis, Part I. Estimation of maximum regional magnitude $m_{\max }$, Pure Appl. Geophys., 152, 413-442.

KIJKO, A. and G. GRAHAM (1999): «Parametric-historic» procedure for probabilistic seismic hazard analysis, Part II. Assessment of seismic hazard at specified site, Pure Appl. Geophys, 154, 1-22.

Lyubushin, A.A., T.M. Tsapanos, V.F. Pisarenko and G.CH. Koravos (2002): Seismic hazard for selected sites in Greece: a Bayesian estimate of seismic peak ground acceleration, Nat. Hazards, 25, 83-98.

MAIN, I.G. and P.W. BurTon (1989): Seismotectonics and the earthquake frequency-magnitude distribution in the Aegean area, Geophys. J. Int., 98, 575-586.

MAKRIS, J. (1973): Some geophysical aspects of the evolution of the Hellenides, Bull. Geol. Soc. Greece, 10, 206-213.

MaKropoulos, K.C. (1978): The statistics of large earthquake magnitude and an evaluation of Greek seismicity, Ph.D. Thesis (Univ. Edinburgh, U.K.), pp. 193.

Makropoulos, K.C. and P.W. BurTON (1984): Greek tectonics and seismicity, Tectonophysics, 106, 275-304

Makropoulos, K.C. and P.W. BurTon (1985): Seismic hazard in Greece, II. Ground acceleration, Tectonophysics, 117, 259-294.

MÄntyniemi, P., T.M. Tsapanos and A. KiJKo (2004): An estimate of probabilistic seismic hazard for five cities in Greece by using the parametric-historic procedure, Eng. Geol., 72, 217-231.

Margaris, V.N., N.P. TheOdUlidis, CH.A. PaPAiOANNOU and B.C. PAPAZACHOS (1990): Strong motion duration of earthquakes in Greece, in Proceedings of the XXII Gen. Assembly ESC, vol. 2, 865-870.

Margaris, V., C.B. Papazachos, CH.A. Papaioannou, N. Theodoulidis, I. Kalogeras and A. Skarlatoudis (2001): Empirical attenuation relations for the strong ground motion parameters of shallow earthquakes in Greece, in Proceedings of the 2nd Congress of Engineering Seismology and Earthquake Engineering, 2830 November 2001, Thessaloniki, Greece.
McKenZIE, D. (1978): Active tectonics of the Alpine-Himalayan belt: the Aegean Sea and surrounding regions, Geophys. J. R. Astron. Soc., 55, 217-254.

Mercier, J. (1977): Principal results of a neotectonic study of the Aegean Arc and its location within the Eastern Mediterranean, in Proceedings of the VI Coll. Geol. Aegean Region, IGMR, Athens, Greece, vol. 3, 12811291.

NEHRP (1994): Recommended provisions for seismic regulations for new buildings, Federal Emergency Management Agency 222A/223A, May, 1 (Provisions) and 2 (Compentary).

Page, R. (1968): Aftershocks and microaftershocks of the Great Alaska earthquake of 1964, Bull. Seismol. Soc. Am., 58, 1131-1168.

Papadopoulos, G.A. and A. KiJKo (1991): Maximum likelihood estimation of earthquake hazard parameters in the Aegean area from mixed data, Tectonophysics, 185, 277-294.

PaPaIOANNOU, CH.A. (1984): Attenuation of seismic intensities and seismic hazard in the area of Greece, Ph.D. Thesis (Aristotle University of Thessaloniki, Greece), pp. 200 (in Greek).

PAPAIOANNOU, CH.A. and B.C. PAPAZAChos (2000): Timeindependent and time-dependent seismic hazard in Greece based on seismogenic sources, Bull. Seismol. Soc. Am., 90, 22-33.

Papazachos, B.C. and P.E. Comninakis (1971): Geophysi$\mathrm{cal}$ and tectonic features of the Aegean Arc, J. Geophys. Res., 76, 8517-8533.

PAPAZACHOS, B. and C. PAPAZACHOU (1997): The earthquakes of Greece (Ziti Publications, Thessaloniki), pp. 304.

Papazachos, B.C., D. Mountrakis, A. Psilovikos and G. LEVENTAKIS (1979): Surface fault traces and fault plane solutions of the May-June 1978 major shocks in the Thessaloniki area, Greece, Tectonophysics, 53, 171-183.

PapazaChos, B.C., V.N. Margaris, N.P. TheOdOUlidis and CH.A. Papaioannou (1992): Seismic hazard assessment in Greece based on strong motion duration, in Proceedings of the 10th WCEE, 1, 425-430.

Papazachos, B.C., CH.A. Papaioannou, B.N. Margaris and N.P. ThEODULIDIS (1993): Regionalization of seismic hazard in Greece based on seismic sources, Nat. Hazards, 8, 1-18.

Papazachos, B.C., D.G. Panagiotopoulos, E.M. Scordilis, G.F. Karakaisis, C.A. Papaionnnou, B.G. KaraKostas, E.E. PAPAdIMITRIOU, A.A. KIRATZI, P.M. HATZIDimitriou, G.N. LeVentakis, P.G. Voidomatis, K.I. PEFTITSELIS and T.M. TSAPANOS (1995): Focal properties of the 13 May 1995 large $\left(M_{s}=6.6\right)$ earthquake in the Kozani area (North Greece), in Proceedings of the $X V$ Congress of the Carpatho-Balkan Geological Association, 17-20 September 1995, Athens, Greece.

Papazachos, B.C., A.A. Kiratzi and B.G. Karacostas (1997): Toward a homogeneous moment-magnitude determination of earthquakes in Greece and the surrounding area, Bull. Seismol. Soc. Am., 87, 474-483.

Papazachos, B.C., P.E. Comninakis, G.F. Karakaisis, B.G. Karakostas, CH.A. Papaioannou, C.B. PapazaCHOS and E.M. SCORDILIS (2000): A catalogue of earthquakes in Greece and surrounding area for the period 550 B.C.-1999, Publication Geophys. Lab., Aristotle University of Thessaloniki, Greece. 
PAPOUlia, J.E. and D. SLeJKo (1997): Seismic hazard assessment in the Ionian Islands based on observed macroseismic intensities, Nat. Hazards, 14, 179-187.

Shebalin, N.V., G.I. Reisner, A.V. Drumea, J.V. ApteKMAN, V.N. SHOLPo, N.Y. StePANEKS and A.J. ZaCharoVA (1976): Earthquake origin zones and distribution of maximum expected seismic intensity for the Balkan region, in Proceedings of the Seminar on Seismic Zoning Maps, 1975, Skopje, Yugoslavia, vol. 2, 68-171.

THEODOULIDIS, N.P. (1991): Contribution to the study of strong ground motion in Greece, Ph.D. Thesis (Aristotle University of Thessaloniki, Greece), pp. 499 (in Greek).

THEODOULIDIS, N and V. LeKIDIS (1996): The KozaniGrevena, Northern Greece, earthquake of May 13,
1995: strong motion data and structural response, Eur. Earthquake Eng., 1, 3-13.

TSAPANOS, T.M and P.W. BURTON (1991): Seismic hazard evaluation for specific seismic regions of the world, Tectonophysics, 194, 153-169.

WAHLSTRÖM, R. and G. GRÜNTHAL (2001): Probabilistic seismic hazard assessment (horizontal PGA) for Fennoscandia using the logic tree approach for regionalization and nonregionalization models, Seismol. Res. Lett., 72, 33-45.

received July 16, 2002; accepted July 20, 2004) 